\title{
FUSÃO DE HORIZONTES: UM CAMINHO PARA A UNIVERSALIDADE? ${ }^{1}$
}

Odair Camati (UCS) $)^{2,3}$

odcamati@hotmail.com

Resumo: $\mathrm{O}$ trabalho se propõe a analisar em que medida a fusão de horizontes desenvolvida por Charles Taylor pode abrir espaço para uma universalização de princípios normativos nos debates multiculturais. Nas sociedades contemporâneas se impõe a discussão em torno do multiculturalismo e, consequentemente, de que forma seria possível reconhecer as mais diversas culturas sem abrir mão de princípios normativos que serviriam como critério de avaliação das próprias práticas culturais. Uma resposta possível apresentada por Taylor afirma que a fusão de horizontes permitiria uma compreensão adequada entre as culturas possibilitando que houvesse um reconhecimento mútuo, além do estabelecimento de princípios mínimos aceitos e respeitados por todos os membros do processo de fusão. $\mathrm{O}$ grande questionamento que emerge nesse ínterim é: como garantir que, de fato, ocorra uma fusão de horizontes? Nesse sentido, quais as condições de possibilidade para que todas as culturas efetivamente alcancem uma compreensão mútua? Caminhamos na direção de defender que a fusão de horizontes é dependente de uma série de condições ideais de difícil efetivação. Uma das críticas que pretendemos desenvolver foi apresentada por Habermas, a saber, a hermenêutica não disporia de elementos necessários para efetuar uma crítica do discurso que pudesse desvelar uma comunicação sistematicamente distorcida.

Palavras-chave: Fusão de horizontes. Crítica. Hermenêutica. Multiculturalismo. Universalidade.

\footnotetext{
${ }^{1}$ Recebido: 09-04-2018/ Aceito: 06-10-2019 / Publicado on-line: 12/04/2020.

${ }^{2}$ Odair Camati é estagiário pós-doutoral na Universidade de Caxias do Sul (UCS), Caxias do Sul, RS, Brasil.

${ }^{3}$ Agradeço à CAPES e à FAPERGS pelo financiamento desta pesquisa.
} 


\section{ELEMENTOS INTRODUTÓRIOS}

O grande desafio das teorias multiculturais é encontrar um equilíbrio entre princípios normativos e o efetivo reconhecimento das mais diversas práticas culturais. $\mathrm{O}$ desafio está posto devido à grande diversidade presente nas sociedades contemporâneas e às mais diversas formas de se lidar com problemas oriundos da própria vida em sociedade. Tais problemas se colocam em menor intensidade em sociedades onde há, ainda que minimamente, uma cultura homogênea. Contudo, a partir da globalização e do intenso movimento humano não é mais possível falar em sociedades humanas culturalmente homogêneas. Com isso, é preciso que se discuta com maior profundidade de que forma estabelecer princípios normativos e, ao mesmo tempo, levar em consideração as contribuições e as vivências particulares oriundas das culturas.

Obviamente que não é possível ignorar que problemas multiculturais não são privilégios das sociedades contemporâneas. Contudo, existem alguns marcos históricos que tornam essa discussão ainda mais importante e necessária contemporaneamente. Pensemos, por exemplo, nas duas grandes guerras mundiais que mudaram fortemente as relações geopolíticas ao redor do mundo, forçando a comunidade humana a pensar em princípios reguladores das suas próprias práticas, tanto nas relações no interior dos Estados, bem como nas relações internacionais. Em decorrência disso nasce em 1948 a Declaração Universal dos Direitos Humanos, um marco fundamental também para o multi- 
culturalismo, pois a partir desse momentosurgem alguns princípios reguladores para a avaliação cultural.

É possível também pensar na Guerra Fria como um elemento importante nesse processo, pois com o seu término tem início um processo de valorização ainda mais latente dos valores liberais e da democracia como forma legítima de governo. Em certa medida, houve um reforço aos valores já apresentados na declaração de 1948. Todos esses elementos permitiram que houvesse uma maior relação entre os diversos grupos humanos, além de uma abertura para que grupos culturais minoritários apresentassem suas demandas históricas. É possível pensar nos grupos indígenas que, mesmo de maneira embrionária, puderam apresentar suas demandas específicas enquanto um grupo cultural historicamente prejudicado pelas políticas assimilacionistas que dominaram a discussão cultural até o século XX.

Desse processo decorrem duas preocupações: a) uma primeira com a abertura para o relativismo cultural e, b) uma segunda com a possibilidade de uma imposição de valores considerados etnocêntricos. No meu entendimento, ambas as preocupações possuem legitimidade tendo em vista que o grande desafio do multiculturalismo, como já mencionei no início, é o equilíbrio entre reconhecimento das particularidades e o estabelecimento de princípios normativos. Desse modo, a preocupação com o relativismo cultural ou o relativismo de valores é necessária, porque com a ausência absoluta de critérios todas as práticas culturais, por mais desrespeitosas que fossem com a dignidade humana, poderiam ser consideradas legítimas.

Por outro lado, não se pode desconsiderar o fato de que as trocas culturais estão fortemente marcadas por relações 
de poder e relações econômicas que, em muitas ocasiões, acabam impondo uma determinada gama de valores culturais. É possível pensar acerca da realidade específica da América Latina que passou por um processo longo e destrutivo de colonização que deixou marcas profundas. Em uma realidade de colonização é antes necessário expurgar uma autoimagem depreciativa ${ }^{4}$ construída durante o período de dominação e, a partir desse momento, pensar em políticas multiculturais adequadas a essa realidade. Tomando o exemplo da América Latina, é possível afirmar que a preocupação com uma política multicultural marcadamente etnocêntrica faz sentido e deve ser tomada em consideração.

Tendo como referência o desafio acima posto é que pretendo analisar a fusão de horizontes apresentada por Charles Taylor. O filósofo canadense toma emprestado o conceito da hermenêutica de Gadamer e visa aplicá-lo nas suas discussões em torno do reconhecimento. $\mathrm{O}$ meu intuito aqui é verificar até que ponto a fusão de horizontes funciona com uma proposta de equilíbrio entre uma política multicultural puramente universalista e uma política multicultural que abra as portas para o relativismo. Além disso, pretendo verificar se a fusão de horizontes pode efetivamente ser aplicada a contextos com fortes embates políticos e geopolíticos.

${ }^{4}$ Para aprofundar essa temática ver a interessante obra de Frantz Fanon, Os condenados da terra. (1979) 


\section{A FUSÃO DE HORIZONTES NA TEORIA POLÍTICA DE CHARLES TAYLOR}

Com os elementos apresentados acima creio que esteja, ao menos minimante, justificada a necessidade de se teorizar acerca do multiculturalismo ao mesmo tempo em que se fazem necessárias políticas multiculturais. Nesse sentido, a teoria de Taylor talvez seja uma das grandes contribuições acerca dessa temática, sendo A política do reconhecimento ${ }^{5} \mathrm{O}$ texto de maior destaque. $O$ reconhecimento, tese principal defendida por Taylor nesse texto, é uma necessidade humana vital tanto para o indivíduo bem como para um grupo de indivíduos.

A tese é de que nossa identidade é moldada em parte pelo reconhecimento ou por sua ausência, frequentemente pelo reconhecimento errôneo por parte dos outros, uma real distorção, se as pessoas ou sociedades ao redor deles lhes devolvem um quadro de si mesmas redutor, desmerecedor ou desprezível. (...) $\bigcirc$ devido reconhecimento não é uma mera cortesia que devemos conceder às pessoas. É uma necessidade humana vital. (TAYLOR, 2000, p. 241-242).

$\mathrm{O}$ entendimento de que o reconhecimento é uma necessidade também para os grupos humanos consiste, em minha análise, na grande contribuição de Taylor para o desenvolvimento do conceito de reconhecimento. Com esse novo entendimento é possível pensar o multiculturalismo como um projeto que crie as condições para o reconhecimento das mais diversas comunidades humanas. $\mathrm{O}$ pensa-

${ }^{5}$ Esse texto está presente em duas obras de Taylor, a saber, Argumentos Filosóficos (2000) e Multiculturalismo(1998). 
dor canadense não delimita a discussão, colocando também em questão o reconhecimento devido às mulheres, aos negros, aos grupos LGBT e outras demandas, contudo, para os fins aqui almejados trabalharemos apenas com grupos culturais.

A não delimitação do sujeito em questão quando se pensa a problemática multicultural consiste, no meu entendimento, em uma limitação do pensamento de Taylor. A grande dificuldade surge quando não há uma explicitação de que sujeitos cabem sob o guarda-chuva do multiculturalismo, confundindo os que estão em busca de reconhecimento não cultural com os que apresentam demandas multiculturais. Seguindo a tese tayloriana todos os sujeitos humanos necessitam de reconhecimento, contudo sob condições diversas. Por isso que o multiculturalismo trata especificamente do reconhecimento de grupos culturais. Parece-me que o conceito de cultura societal, cunhado por Kymlicka dá conta dessa dificuldade:

[...] uma cultura que proporciona aos seus membros umas formas de vida significativas através de toda a gama de atividades humanas, incluindo a vida social, educativa, religiosa, recreativa e econômica, abarcando as esferas da vida pública e da vida privada. Essas culturas tendem a se concentrar territorialmente, e se baseiam em uma língua compartilhada. (KYMLICKA, 1996, p. 112).

Com a delimitação apresentada por Kymlicka julgo que a discussão multicultural tenha logrado, ainda que passível de crítica, uma caracterização que nos permite identificar mais claramente qual o objeto em discussão. Nem todos os grupos culturais estão concentrados territorialmente e muitos outros não possuem uma organização política claramente estruturada, mas possuem elementos suficientes para se 
compreenderem como um grupo cultural ao fornecerem aos seus membros possibilidades significativas de escolha. Dentro dessa conceituação estão contidos aqueles grupos humanos, que em decorrência da imigração, se encontram em outros Estados. Tendo em vista que possuem demandas diferenciadas se colocam também em um patamar diferente de reivindicação. Esses grupos não são ignorados nas discussões multiculturais.Seria possível pensar no tratamento desenvolvido por Kymlicka para essa questão, contudo, não vamos nos aprofundar visto não ser o objeto do presente trabalho. ${ }^{6}$

Por mais que Taylor não tenha feito essa distinção, o seu texto é um marco importante que abre a possibilidade para discutir o reconhecimento de grupos culturais. Ainda que seja possível delimitar o campo de análise do multiculturalismo, o problema de como equilibrar universalismo com o particularismo ainda permanece. A Declaração de 1948 apresentou critérios "universais" para avaliar tanto práticas individuais bem como práticas coletivas. Contudo, mesmo que carregue no nome a universalidade, tal Declaração não alcançou efetivamente a aceitação universal. $\mathrm{O}$ argumento consiste em afirmar que a Declaração é fruto de uma cultura específica e que não reflete a diversidade humana.

Com isso coloca-se novamente o desafio de pensar critérios que sejam aceitos por todos os povos, refletindo assim, a diversidade presente nas mais diversas comunidades humanas. Há quem defenda que os valores da tradição libe-

${ }^{6}$ Para maiores esclarecimentos sobre esse tema, cf. KYMLICKA, 1996. 
ral, afirmados na Declaração, são os valores adequados para avaliar as culturas. Considero que a teoria liberal do multiculturalismo desenvolvida por Kymlicka seja o melhor exemplo dentro dessa perspectiva. Para o filósofo já dispomos de critérios adequados para avaliar as práticas culturais, com isso, o que temos de fazer é encontrar a melhor maneira de liberalizar àquelas que ainda não comungam dos mesmos valores. Obviamente que a imposição forçosa está descartada, mas de qualquer maneira já existiriam critérios previamente estabelecidos.

Tomando em consideração o fato que os valores liberais são fruto também de uma cultura específica e que não gozam de aceitação global, proponho repensar a sua validade universal. Com isso não estou afirmando que os valores liberais não sejam adequados, estou apenas pensando sobre sua pretensa aceitação universal. É muito provável que, em princípio a tradição liberal forneça as melhores condições para a vivência da diversidade, contudo, é questionável o fato de tomá-la como pressuposto universal. Mesmo diante da abertura propiciada pelos valores liberais, é possivel verificar que em muitas ocasiões o liberalismo apresenta dificuldades para dialogar com a diferença cultural porque está demasiadamente ancorado na defesa de interesses individuais.

O próprio Taylor se propõe a pensar uma forma de liberalismo capaz de reconhecer metas coletivas e não apenas metas individuais. Proponho chamar a isso de liberalismo brando ou liberalismo com premissas comunitaristas. $O$ grande objetivo é aliar valores individuais, como a igualda- 
de e a liberdade, com metas coletivas como a sobrevivência da cultura francesa no Quebec ${ }^{7}$. Um modelo liberal dessa natureza seria suficiente para reconhecer e acomodar práticas culturais minoritárias no interior de sociedades liberais. O problema permanece com relação àquelas sociedades que não se compreendem como liberais, não comungando, portanto, dos mesmos valores. O problema se torna ainda mais premente quando da relação entre Estados porque entram em cena os problemas geopolíticos que, sem dúvida, colocam maiores dificuldades no processo de reconhecimento da diversidade cultural.

Uma possibilidade para se superar essa dificuldade é a fusão de horizontes, originalmente proposta pela hermenêutica gadameriana, mas que é tomada de empréstimo por Taylor na sua filosofia política. Em que consiste a fusão de horizontes proposta por Taylor e como ela pode responder aos desafios do multiculturalismo? Esses são os questionamentos que pretendo enfrentar nesse momento. Após explicitar o que seja a fusão de horizontes, proponho-me a analisar as críticas a ela direcionadas, especialmente por Habermas e, que mais tarde, foram repensadas por Ricoeur. Em linhas gerais esse é o percurso da sequência do presente trabalho.

Uma primeira constatação quando nos deparamos com a obra de Gadamer se refere a não tematização direta do que seria a fusão de horizontes. Entretanto, esse é um con-

\footnotetext{
${ }^{7} \mathrm{O}$ Quebec é a segunda maior província canadense em termos populacionais e se compreende como culturalmente distinta do restante do Canadá inglês, visto que tem no francês a sua língua oficial. A partir disso possui maior autonomia na relação com as demais províncias canadenses, exatamente para preservar sua especificidade cultural.
} 
ceito central para entender a sua teoria. Não vou aqui retomar a teoria de Gadamer, apenas farei uso dos elementos que, nesse momento, considero importantes para entender a fusão e que servirão para verificar sua eficácia política. Também não buscarei respostas para entender o porquê de Gadamer não ter escrito uma seção para tratar dessa temática, pois isso cabe aos intérpretes gadamerianos preocupados com o entendimento mais atento do seu pensamento em sua totalidade.

Quando pensamos em fusão de horizontes dois são os conceitos imbricados, fusão e horizonte. Parece-me importante pensá-los isoladamente para em seguida entender o que representam unidos. Fusão, segundo o dicionário Aurélio significa "ato ou efeito de fundir ou fundir-se; derretimento pela ação do calor. Mistura, liga. Aliança, união. (...) Processo de transformação de dois elementos contíguos num terceiro."(FERREIRA, 2009, p. 950).Temos um significado oriundo da física que indica que quando ocorre uma fusão duas substâncias diferentes podem formar uma nova substância. Além disso, podemos falar em fusão empresarial quando duas empresas se unem para formar uma nova e mais forte organização, podemos falar ainda em fusão partidária quando de uma eleição os partidos decidem pela fusão para tornarem-se mais fortes. Todos esses elementos indicam que, numa fusão, os elementos sempre acabam transformados e disso normalmente surge um novo elemento.

Horizonte por sua vez possui uma concepção mais abrangente:

Linha circular que limita o campo de nossa observação visual, e na 
qual o céu parece encontrar-se com a superfície terrestre (considerada uma esfera perfeita). Extensão indefinida, espaço. Perspectiva ou probabilidade de desenvolvimento, de progresso, de melhoria.(FERREIRA, 2009, p. 1057).

Horizonte, em última instância, é o campo de visão que está diante de nós e que nos possibilita ver determinados elementos e não ver a outros. Nesse sentido, um horizonte é o que vemos a partir de um determinado ponto de vista, mas não é o ponto de vista nele mesmo. Em outras palavras, o horizonte é condição de possibilidade para a existência de um ponto de vista particular ou singular. Nessa mesma linha um horizonte nunca é plenamente alcançado ou compreendido, sempre pode ser ampliado visando novas compreensões. Parece ser exatamente esse o entendimento de Gadamer.

Horizonte é o âmbito de visão que abarca e encerra tudo o que pode ser visto a partir de um determinado ponto. Aplicando esse conceito à consciência pensante, falamos então da estreiteza do horizonte, da possibilidade de ampliar o horizonte, da abertura de novos horizontes, etc. A linguagem filosófica empregou essa palavra, sobretudo desde Nietzsche e Husserl, para caracterizar a vinculação do pensamento à sua determinidade finita e para caracterizar o modo pelo qual o seu alcance visual é gradualmente ampliado. (GADAMER, 2003, p. 399-400).

É sempre possível ampliar o próprio horizonte e passar a compreender de forma mais adequada a si mesmo e ao outro. Esse processo normalmente vem acompanhado por uma compreensão mais clara do próprio sujeito que se dispõe a fundir o seu horizonte, pois na medida em que amplia o horizonte, amplia também a sua forma de ver o 
mundo e a si mesmo. A conclusão desse raciocínio é que a abertura para fusão de horizontes é a abertura para o compreender, primeiro o compreender a si mesmo e também compreender o outro. Diante desses elementos é necessário questionar: por que existem tantas dificuldades no processo de fusão de horizontes, especialmente quando estão em questão dois sujeitos com vivências fortemente distintas? A resposta está nas condições para uma efetiva fusão.

Para que de fato ocorra uma fusão de horizontes é preciso um exercício profundo de auto compreensão e de abertura para compreender o outro. $\bigcirc$ processo de compreensão do outro exige que o diálogo se efetue em uma linguagem compreensiva para ambos os atores envoltos e que esteja livre de possíveis distorções. $\mathrm{O}$ primeiro passo, abrir-se para a fusão, é um processo que depende dos indivíduos e dos grupos, ou seja, está atrelado ao desejo de realmente compreender o outro e melhor compreender a si mesmo. Nesse sentido, o primeiro desafio para a efetivação de uma fusão está atrelado à subjetividade de indivíduos e grupos e, portanto, dependente da autocompreensão.

$O$ segundo momento, dialogar a partir de uma linguagem compreensiva e sem distorções, coloca o desafio do desenvolvimento de vocabulários ampliados que sirvam como meio para o diálogo. Aqui, são dois os desafios, o primeiro é reconfigurar uma linguagem que permita o diálogo ou, em outras palavras, é preciso traduzir as diferentes formas de conceber um mesmo objeto de tal forma que todos o compreendam da mesma forma. O segundo desafio, que me parece mais complexo e que aprofundaremos com Habermas, é eliminar qualquer distorção sistemática no percurso do diálogo. 
Além desses elementos iniciais de abertura e compreensão, faz-se importante aceitar uma possível mudança de concepção a partir do diálogo com o outro. Não faz sentido colocar-se em uma postura de diálogo e não estar disposto a mudar a concepção pessoal. Nessa linha, a fusão não serve para simplesmente convencer um indivíduo ou um grupo cultural de que princípios já previamente estabelecidos são os mais adequados. Obviamente que, como Gadamer (2003, p. 368) nos recorda, não podemos nos desvencilhar de nossos preconceitos em qualquer atividade que realizarmos, pois eles são o nosso ponto de partida, mas podemos abrir a possibilidade de uma mudança e/ou adequação dos mesmos.

O passo seguinte é a adoção de uma posição que esteja de acordo com um pluralismo razoável, para usar uma terminologia rawlsiana. Por mais que, a partir da fusão de horizontes, não se chegue a um denominador comum, é possível alcançar um patamar de respeito à diversidade de posições e de formas de vida. Entretanto, para que um pluralismo razoável seja possível é preciso pensar em possíveis limites ou critérios para a fusão de horizontes. $\mathrm{O}$ que estou afirmando é que, por mais que exista uma abertura para o outro, não se pode permitir que tal abertura leve a resultados inadequados, tais como uma completa subordinação de um sobre ou outro, ou a destruição de um dos sujeitos envoltos no processo. Penso aqui, por exemplo, na tradição Ocidental dos direitos humanos como um possível limite para uma fusão de horizontes que aconteça em um contexto ocidental. A pergunta que coloco é: são esses mesmos critérios suficientes para permitir uma fusão com culturas não ocidentais? 
Tendo em vista as dificuldades listadas acima, apresento mais um elemento importante no processo de fusão, a saber, a possibilidade de constante revisão. Não há um ponto final e definitivo na busca de compreender-se e compreender o outro, especialmente quando são dois sujeitos humanos ou grupos humanos que estão envoltos nesse ínterim. O mesmo ocorre, acredito que em proporções menores, quando da compreensão de um texto por parte de um sujeito. $\mathrm{O}$ meu foco se direciona para a relação entre sujeitos ou grupos porque a tentativa tayloriana é de utilizar esse conceito no âmbito da negociação político/cultural.

Antes de verificar como Taylor pretende usar a fusão de horizontes no âmbito da sua filosofia política, apresento como Abbey sintetiza as grandes os pressupostos para a fusão de horizontes.

Isto inclui o genuíno desejo e disposição para conhecer o que é o outro, a habilidade de não descartar coisas que parecem como necessariamente irracionais, o respeito pela diferença, a habilidade para mudar, a coragem para questionar os próprios pressupostos e assim por diante ${ }^{8}$. (ABBEY, 2000, p. 163-164).

Os critérios que apresentamos acima, resumidos por Abbey, tratam da possibilidade de abertura de um indivíduo ou de um grupo de indivíduos diante de outro sujeito ou outro grupo de sujeitos, contudo, ainda não me parece suficiente quando estamos lidando com uma teoria política que pretende dar conta do multiculturalismo. Por isso, espera-se de quem faz uso desses conceitos que os esclareçam

${ }^{8}$ Tradução livre. 
e indiquem como serão desenvolvidos no interior de uma teoria política. Exatamente essa a expectativa que Taylor cria quando afirma que a fusão de horizontes é o caminho para uma efetiva compreensão entre as mais diversas culturas, permitindo assim o reconhecimento de todos os grupos humanos.

Quando da análise das culturas, Taylor propõe que adotemos como pressuposto que, todas as culturas que animaram ou animam comunidades humanas por um período de tempo considerável, possuem algo de importante para seus próprios membros e também para as demais comunidades humanas. Entretanto, o pressuposto não é suficiente para o efetivo reconhecimento, "tem de haver juízos reais de igual valor aplicados aos costumes e às criações dessas diferentes culturas." (TAYLOR, 2000, p. 271). Para o filósofo canadense a fusão de horizontes seria capaz de nos fornecer os elementos necessários para a aplicação de juízos de valor entre as diferentes culturas.

O problema que parece surgir dessa solução tayloriana tem relação com as condições que mencionei acima, pois a fusão coloca uma alta carga de exigência nos participantes que nem sempre será bem sucedida. "A fusão nunca ocorre livre de riscos." (GRONDIN, 2005, p. 405). Tendo em vista os riscos presentes em todas as fusões é que, segundo minha compreensão, falta na teoria de Taylor a construção de critérios para, em alguma medida, diminuir os possíveis riscos. Já mencionei acima que o filósofo canadense, ao propor um liberalismo brando, acaba por filiar-se aos valo-

${ }^{9}$ Tradução livre. 
res da tradição liberal, especialmente a liberdade e a igualdade. Isso significa que para um contexto liberal existem critérios que não permitem grandes riscos. Contudo, quando da fusão de culturas não liberais não é possível afirmar os mesmos critérios. Ou, até seria possível, sob o risco de um etnocentrismo e de um consequente não reconhecimento ou reconhecimento errôneo. Por isso, falta a Taylor pensar em critérios normativos que permitam que o processo de fusão transcorra sem graves distorções.

Contudo, é ainda possível pensar em dificuldades no processo de fusão que ocorram no interior da tradição liberal. Pois mesmo nesse contexto é possível que surjam problemas decorrentes de uma comunicação sistematicamente distorcida. Obviamente que a referência para desenvolver essa crítica é o texto de Habermas intitulado A pretensão de Universalidade daHermenêutica escrito como uma crítica à hermenêutica gadameriana. $O$ contexto da crítica que estou propondo se difere daquele de Habermas, mas acredito que mesmo assim se adeque à crítica que venho desenvolvendo.

Habermas encontra um limite na pretensão de universalidade da hermenêutica:a impossibilidade de alcançar o patamar da crítica. A partir do entendimento gadameriano que "Ser que pode ser entendido é linguagem", contrapõese a crítica habermasiana de que as distorções da linguagem não poderiam ser identificadas pela hermenêutica, mas somente pela crítica. Isso ocorre porque nem sempre é possível perceber os elementos que estão imbricados em uma linguagem sistematicamente distorcida sem recorrer a um olhar crítico que se compreenderia como uma hermenêutica profunda. Em outros termos, segundo a hermenêutica de Gadamer seria possível compreender a partir da própria 
linguagem. Por outro lado, Habermas afirma a impossibilidade da compreensão sem o elemento que pode ser apresentado pela crítica, nesse sentido, a linguagem por si só não compreenderia possíveis distorções.

Nós só estaríamos legitimados a identificar o acordo fundamental, que segundo Gadamer sempre subjaz ao entendimento frustrado, com o respectivo estar-de-acordo fático, se pudéssemos estar seguros de que todo consenso ensaiado no medium da tradição lingüística (sic) se realizou sem coação e não distorcidamente. Ora, a experiência hermenêutica profunda nos ensina que na dogmática do contexto da tradição não se impõem só a objetividade da linguagem em geral, mas também a repressividade de uma relação de violência (ou: poder), relação que deforma a intersubjetividade do entendimento como tal e distorce sistematicamente a comunicação em linguagem corrente. (HABERMAS, 1987, p. 63).

A preocupação de Habermas se direciona para as condições em que ocorre o diálogo hermenêutico. Assim, se ficarmos apenas no nível da linguagem, que se desenvolve a partir de um consenso prévio, sem verificarmos em que condições esse procedimento ocorreu, não será possível perceber as distorções oriundas de coações ou de relações de poder. Em última instância, Habermas chama atenção para as condições nas quais um diálogo se desenvolve, poismuitos elementos,externos ao próprio diálogo, podem acabar influenciando diretamente nas conclusões do processo de compreensão. Essa é uma conclusão aparentemente óbvia, mas que deve ser mais bem analisada.

Tendo em vista que me proponho a verificar se a fusão de horizontes pode nos oferecer um caminho possível para 
estabelecer alguns princípios normativos com validade universal quando estivermos discutindo o multiculturalismo, parece-me que as condições em que esse processo ocorrer são essenciais. Não me proponho a realizar uma análise geral da teoria de Gadamer e muito menos das críticas de Habermas, estou me valendo dessas teorias para a verificação da fusão de horizontes. Na sequência do trabalho me proponho ainda a voltar mais especificamente na questão crítica da hermenêutica com as repostas de Ricoeur a Habermas.

O que acredito ser uma contribuição importante para a hermenêutica, e aqui no meu caso mais especificamente para a fusão de horizontes, é pensar em que condições ocorreria um diálogo livre de coações e de distorções. As coações dizem respeito, em grande medida, aos problemas decorrentes de relações de poder ou relações econômicas. No caso do multiculturalismo temos, por um lado, grupos majoritários fortemente consolidados e, por outro, grupos minoritários com enormes dificuldades até mesmo na sua luta pela sobrevivência.Os aspectos políticos e econômicos possuem forte influência nesse processo e, se não balanceados, impedem o efetivo diálogo entre os diferentes grupos. As coações, tanto se apresentam claramente, como em alguns casos podem estar veladas ou escondidas atrás de falsos mecanismos de reconhecimento.

Sendo assim, é possível determinar quando um diálogo ocorre sem coações? Acredito que não há uma resposta definitiva para essa questão, mas os elementos listados acima podem indicar um direcionamento. Abertura, escuta do outro, possibilidade de mudança da própria concepção, abertura para uma revisão constante das conclusões podem 
apresentar indícios de que os elementos gerados pelo diálogo estão livres de coações. Contudo, ainda não são suficientes para verificar a existência de coações decorrentes de relações de poder ou jogos de interesses. É preciso verificar criticamente, fazendo uso de uma hermenêutica profunda, nos termos de Habermas.

É ainda mais problemático perceber as distorções na comunicação decorrentes de ideologias ou de précompreensões que não são devidamente verificadas no processo de compreensão. As distorções sistemáticas nem sempre são percebidas pela análise do discurso em linguagem natural, sendo necessário um passo atrás para perceber possíveis distorções. No entendimento de Habermas a hermenêutica não nos possibilitaria essa análise e, portanto, acabaria imbricada em distorções veladas. As distorções são decorrentes de ideologias ou de elementos patológicos que, foram em alguma medida, racionalizados. $O$ exemplo habermasiano de um neurótico que atua a partir de uma linguagem publicamente incompreensível até mesmo para ele próprio, nos ajuda a compreender o argumento. Não é possível compreender as suas ponderações a partir da linguagem natural ou pública porque sua atuação não se coloca numa tal linguagem. Habermas aponta que nessas circunstâncias a hermenêutica não possibilitaria uma compreensão adequada porque não seria capaz de verificar de onde procedem as colocações neuróticas.

No caso específico de um comportamento neurótico é necessário que um profissional adequado ressimbolize $\mathrm{o}$ cenário de onde fala o neurótico. Com isso permite-se uma compreensão pública daquilo que antes estava presente apenas na cena criada por um indivíduo que ao se deparar 
com determinadas cobranças ou frustrações cria uma cena específica que acredita poder libertá-lo.

A compreensão cênica distingue-se da simples compreensão hermenêutica do sentido pela sua força explanatória. Ela deduz o sentido das manifestações vitais especificamente incompreensíveis somente na medida em que consegue, com a reconstrução da cena original, esclarecer também as condições da gênese do sem-sentido. (HABERMAS, 1987, p. 46).

A hermenêutica não possibilitaria a compreensão da gênese de uma comunicação sistematicamente distorcida, impossibilitando assim uma análise crítica das condições em que se desenvolve um diálogo entre sujeitos com vivências fortemente distintas. A mesma argumentação é utilizada por Habermas para se referir às ideologias. Portanto, se não for possível compreender a gênese, ou seja, como as neuroses e as ideologias foram formadas e desenvolvidas, não será possível escapar às armadilhas da distorção no diálogo hermenêutico, e da mesma forma no processo de fusão de horizontes.

Somente com uma análise crítica dos diferentes discursos distorcidos haveria a possibilidade de compreensão entre os sujeitos. Nas discussões multiculturais isso me parece ainda mais evidente, porque todos os grupos culturais estão em busca de reconhecimento efetivo de suas práticas, contudo, é preciso antes que os sujeitos que lutam por reconhecimento tenham compreendido uns aos outros. No meu entendimento a hermenêutica nos oferece tal possibilidade, mais ainda precisa caminhar no sentido de pensar criticamente as relações que estão imbricadas durante o processo de compreensão.

Nesse sentido, também o pensamento político de Ta- 
ylor está carente de critérios para garantir o encontro entre as culturas. Por mais que exista uma disposição para o diálogo e para uma possível mudança dos próprios conceitos, é necessário pensar em condições de possibilidade reais do diálogo. Quer dizer, de nada adianta uma disposição se não houver uma linguagem minimamente livre de distorções que permita que a disposição se concretize. Ou ainda, de nada adianta fundir horizontes e não estabelecer princípios normativos que guiem as práticas culturais.

Nessa linha argumentativa, Ricoeur apresenta algumas contraposições a essa arguição. Para o pensador francês, Habermas e Gadamer falam a partir de pontos diferentes, mas que, em última instância, possuem um ponto de partida comum, a saber, a hermenêutica da finitude. Em outras palavras, significa que há um limite claro tanto para o desenvolvimento de um diálogo hermenêutico, bem como para uma crítica da comunicação sistematicamente distorcida. A partir da compreensão da finitude, Ricoeur propõe que pensemos como é possível alcançar a tão desejada emancipação proposta por Habermas tendo como referência exclusivamente a tradição iluminista e, além disso, pergunta pela possibilidade de uma experiência de comunicação que não esteja compreendida num determinado espaço e num tempo circunscrito.

Por minha parte, parece-me que uma crítica nunca pode ser primeira nem última; só se criticam distorções em nome de um consenso que não podemos antecipar simplesmente no vazio, sobre uma forma de uma idéia (sic) reguladora, se esta idéia (sic) não for exemplificada. (RICOEUR, 1978, p. 367). 
O argumento de Ricoeur consiste em mostrar que qualquer crítica que viermos a desenvolver está sempre ligada a um determinado contexto que, em alguma medida, o precede. Nesse sentido, para que seja possível compreender uma determinada crítica é importante localizar de que ponto se está falando e para quem se está direcionando tal crítica. Colocando em outros termos, a hermenêutica nunca perde de vista a preocupação com o lugar de onde fala. Com isso Ricoeur intenta mostrar que uma meta hermenêutica nos moldes de Habermas não é possível se descolada do lugar de onde fala.

Porque, afinal de contas dirá ohermeneuta: de onde vocês falam quando recorrem à Selbstreflexion,senão desse lugar que vocês mesmos denunciaram como sendo um não-lugar, o não-lugar do sujeito transcendental? É do fundo de uma tradição que vocês falam. Talvez essa tradição não seja a mesma que a de Gadamer. Talvez seja justamente a da Aufklàmng, enquanto que a de Gadamer seria a do romantismo. Mas ainda é uma tradição, a tradição da emancipação, mais que a tradição da rememoração. A crítica também é uma tradição. (RICOEUR, 1983, p. 145).

Parece-me que o argumento do filósofo francês apresenta claramente a ideia de que não seria possível realizar uma crítica a partir de um não-lugar, mas ainda assim permanece o questionamento acerca da capacidade da hermenêutica de identificar os problemas de uma comunicação sistematicamente distorcida. A resposta caminha na direção de afirmar que, ser que pode ser entendido é linguagem, assim, até mesmo a própria crítica seria possível apenas através da lin- 
guagem. Portanto, segundo Ricoeur, o exercício da pergunta e da resposta amparado na busca de compreender a "coisa mesma" nos levaria a um distanciamento suficiente para perceber possíveis distorções.

Independentemente de a hermenêutica ser suficiente ou não para perceber possíveis distorções, é imprescindível que haja durante o processo de fusão uma análise mais detalhada a fim de garantir uma compreensão adequada de todos os sujeitos que se colocam no processo de fusão de horizontes. Considero decisivo o argumento de Ricoeur sobre a impossibilidade de se realizar qualquer crítica a partir de um "não-lugar", mas isso não impede que seja possível pensar em elementos que garantam que todos os sujeitos partam das mesmas condições e que se lhes seja apresentada uma linguagem suficientemente compreensiva. Nesse sentido, o argumento da finitude me parece adequado nessa discussão, mas ainda é insuficiente para garantir uma fusão de horizontes desprovida de incompreensões.

Em linhas gerais, o que estou defendendo nesse texto pode ser resumido da seguinte forma. Quando da busca por compreensão entre culturas e da possibilidade da atribuição de princípios comuns, o filósofo canadense Charles Taylor propõe que a fusão de horizontes pode servir como parâmetro para alcançar tal objetivo. Habermas, por sua vez, afirma não ser possível alcançar esse objetivo porque a hermenêutica não é capaz de crítica e, assim, não seria suficiente para analisar possíveis distorções sistemáticas no transcurso do diálogo. Ricoeur, para responder a essa objeção, afirma que nenhuma crítica pode ser desenvolvida a partir de um não 
lugar, dessa forma qualquer elemento crítico também nasceria de um determinado tempo e um determinado espaço.

A partir desses elementos, estou afirmando que a teoria tayloriana ancorada na hermenêutica não alcança um patamar suficiente para afirmar que pode oferecer os elementos necessários para que uma fusão de horizontes transcorra de maneira equitativa. Isso se deve ao fato de que não oferece um caminho adequado para pensar nas condições sociais, políticas e econômicas em que se desenvolverá uma fusão de horizontes, além de não apresentar elementos para estabelecer uma linguagem suficientemente compreensiva a todos os membros de um processo de fusão. Em outros termos, o problema da teoria tayloriana reside em não apresentar condições de possibilidade para o encontro entre diferentes horizontes. Tudo caminharia para que Taylor levasse adiante esse debate ao propor a fusão de horizontes como possibilidade de compreensão entre culturas distintas, mas não é isso que se verifica no pensamento tayloriano. Nesse sentido, falta um desenvolvimento mais claro em Taylor de como, efetivamente, a fusão de horizontes servirá de abertura para a construção de princípios universais.

Diante desses elementos, considero que ainda permanece em aberto a discussão em torno da possibilidade ou não de crítica na hermenêutica, pois por mais que todo o processo se desenvolva por meio da linguagem, é possível que ocorram distorções nem sempre percebidas pela análise da linguagem natural. Dentro da discussão que proponho nesse texto sobre a possibilidade de reconhecimento cultural aliado ao estabelecimento de princípios com validade 
universal, é preciso avançar tanto na hermenêutica, bem como na crítica, no sentido de propor elementos que garantam a compreensão e o estabelecimento de valores com validade universal a partir do encontro entre diferentes culturas.

\section{CONSIDERAÇÕES FINAIS}

A partir da reflexão acima apresentada, julgo que ainda permanece o problema das condições em que uma compreensão será desenvolvida. Por mais que a hermenêutica possa perceber possíveis incompreensões na linguagem através do exercício da pergunta, é preciso, em algum momento, voltar um pouco e analisar sob quais condições ocorreu o diálogo ou a fusão de horizontes. Uma fusão de horizontes que almeje a construção de princípios normativos para o multiculturalismo não pode se desviar da tarefa de elucidar com clareza quais os elementos necessários para que o processo ocorra de maneira que a todos tome em consideração. Por isso também deve, segundo minha compreensão, estabelecer alguns limites no próprio desenvolvimento do processo. Em termos de Ocidente podemos afirmar que os direitos humanos promulgados em 1948 são um limite claro que pode impedir possíveis atitudes inadequadas daqueles que se dispõem a fundir seus horizontes. Mas esses critérios servem para todas as demais comunidades humanas? Tendo a acreditar que não. E possuímos tais critérios? Ainda não.

Diante disso, percebo duas dificuldades da fusão de horizontes. A primeira é a sua insuficiência de pensar em efetivas condições para um diálogo não distorcido. E a 
segunda diz respeito à passagem do aspecto compreensivo para o aspecto normativo. A primeira dificuldade está muito conectada com a crítica de Habermas, já a segunda está mais direcionada para o problema do multiculturalismo. Em última instância, a fusão seria um processo para apresentar critérios normativos, mas antes disso, é preciso encontrar elementos que nos garantam que uma fusão de horizontes não nos levará a resultados descabidos. Temos, portanto, uma dificuldade em termos compreensivos e uma dificuldade em termos normativos. Por conseguinte, proponhocomo conclusãoa insuficiência da fusão de horizontes, nos termos apresentados pela teoria tayloriana, para o estabelecimento de princípios normativos universais no interior de discussões multiculturais.

\begin{abstract}
The present work intends to analyze to what extent the fusion of horizons developed by Charles Taylor can open space for a universalization of normative principles in multicultural debates. In the contemporary societiesthere is a need to discuss multiculturalism and, consequently, how it would be possible to recognize the most diverse cultures without giving up normative principles that would serve as a criterion for evaluating one's cultural practices. A possible answer presented by Taylor states that a fusion of horizons would allow an adequate understanding between cultures making possible mutual recognition, in addition to the establishment of minimal principles accepted and respected by all members of the fusion. The great question is: how to ensure that, in fact, a fusion of horizons occurs? In this sense, what are the conditions of possibility for all cultures to effectively achieve mutual understanding? We are defending that the fusion of horizons is dependent on a series of ideal conditions that can hardly be effective. One of the criticisms that we intend to develop was presented by Habermas, that is, hermeneutics would not have the necessary elements to make a critique of discourse that could reveal a systematically distorted communication.
\end{abstract}

Keywords. Fusion of horizons. Criticism. Hermeneutics. Multiculturalism. Universality. 


\section{REFERÊNCIAS}

ABBEY, Ruth. Charles Taylor. Princeton, Princeton University Press, 2000.

FANON, Frantz. Os Condenados da Terra. Trad. de José Laurêncio de Melo. $2^{\circ}$ Ed. Rio de Janeiro: Editora Civilização Brasileira S. A., 1979.

FERREIRA, Aurélio Buarque de Holanda. Novo dicionário Aurélio da língua portuguesa. $4^{\circ} \mathrm{Ed}$. Curitiba: Positivo, 2009.

GADAMER, H. G. Verdade e Método I. Petrópolis: Vozes, 2003.

GRONDIN, Jean. La fusion des horizons. La version gadamérienne de l'adaequatio rei et intellectus ? Archives de philosophie, 2005, Tome 68, p. 401-418.

HABERMAS, Jürgen. A pretensão de Universalidade da Hermenêutica. In: HABERMAS, J. Dialética e Hermenêutica. Trad. Álvaro Valls. Porto Alegre: L\&PM, 1987.

KYMLICKA, Will. Ciudadanía multicultural. Una teoría liberal de losderechos de las minorias. Trad. Carme Castells Auleda. Barcelona: EdicionesPaidós Ibérica, 1996.

RAWLS, John. A Theory of Justice. Cambridge: Harvard UniversityPress, 2000 (Revised Edition). 
RICOEUR, Paul. Interpretação e Ideologias. Trad. de Hilton Japiassu. Rio de Janeiro: Francisco Alves, 1983.

. O conflito das interpretações. Trad. dede Hilton Japiassu. Rio de Janeiro: Imago, 1978.

TAYLOR, Charles. Multiculturalismo. Trad. de Marta Machado. Lisboa: Instituto Piaget, 1998.

Argumentos filosóficos. Trad. de Adail Ubirajara Sobral. São Paulo; Edições Loyola, 2000. 